\title{
MONOCULAR DIPLOPIA OCCURRING IN CASES OF SQUINT
}

BY

\author{
E. E. CASS \\ LONDON
}

MoNocular diplopia which is sometimes complained of and at other times can be evoked artificially, is found in cases of squint which have no physical defect in the lenses, corneae, pupils, retina etc., to account for this phenomenon, but have some abnormal retinal correspondence. As early as 1854 , von Graefe had remarked upon the anomalous diplopia which occurred after cases of operation for squint, and that in some cases the diplopia would change from moment to moment, being at times crossed and at others uncrossed. This change in the diplopia was due to the fact that in these cases which have both an abnormal and a normal correspondence, each retinal point has two space values according to whether the abnormal correspondence or the normal correspondence is being used. But it was Javal, who, due to the bringing to consciousness of the two space values simultaneously, actually noted a further stage of this phenomenon and described the first case of monocular diplopia occurring in a squinting child. His case, which he examined in 1864 , was that of an alternating squint which dated from birth and had some weakness of the left external rectus. On examining the patient's binocular vision by means of a stereoscope, Javal found that he had monocular diplopia with the left eye, and concluded that the patient saw " one image in correct projection and the other image in false projection." Unfortunately, this case, as many cases of squint do, disappeared . after six weeks, and when Javal wrote to find out what had happened, the patient replied that von Graefe had operated upon him and that he was now suffering from a crossed binocular diplopia. Javal, in his book on squint, quotes a few further cases of this monocular diplopia, usually associated with poor visual acuity in the squinting eye.

Classen, in $18 \% 0$, noted the second example and described the case of a patient aged 28 years, who had diplopia following an operation for a right convergent squint associated with amblyopia and noted that at times the diplopia was crossed and at others uncrossed. After operation, on covering the left eye and fixing with the right eye and then uncovering the left eye quickly, the patient saw three images of the light, a central clear one seen by the left eye and two faint images seen by the right eye, one on the left and one on the right of the clear image. The author, however, simply says 
that this phenomenon can be ignored and he concerns himself solely with the binocular diplopia which was at times crossed and at others uncrossed.

Gaudenzi, in 1897, showed that in cases of squint with a false correspondence the central impression of the eye could be projected to two different positions in space without any movement of the eyes having taken place, that is to say, each retinal point had two space values, a congenital and an acquired, and he says in certain cases these two space values can be brought to consciousness at the same time, and this is the explanation of monocular diplopia.

Tschermak, in 1899, in his auto-observations, discovered that if he fixed with one eye and then covered this same eye but still maintained the eye in the position of fixation, he could get monocular diplopia with the squinting eye. The position of the double images corresponded to the position of both foveal after images.

Bielschowsky examined with great care and much detail a case of monocular diplopia which differed somewhat from the previously recorded cases. His case was a man aged 18 , a left convergent strabismus with a very amblyopic squinting eye (i.e., counting fingers at six metres), who lost his good eye and after this suffered from a very troublesome monocular diplopia. This case also had eccentric fixation, but during the course of time, he learnt to fix with the macula, although at the beginning when he tried to fix with the macula he thought he was looking to the left of the object fixated and not at it. His vision improved to $6 / 36$ and in the following year it improved to $6 / 18$ and during that period a change took place in the appearance of the two images. At first the patient called the left image the false image and this image was dimmer, but when he learned to fix with his macula the left image was clearer and the right was fainter. This case, as I will explain later, is more complicated than most cases of monocular diplopia because not only did it have two space values for each retinal point, but there were two starting points for orientation and at times the eccentric point was used and at other times the macula. Also the muscle sense was at fault and the patient did not know the position of his eye, for, as I have previously said, when he was learning to fix with his macula he thought he was really looking to the left of the object fixated.

Travers has reported four cases of monocular diplopia which he obtained whilst stimulating macular binocular vision in cases of squint with false correspondences. Most of the recent work on this subject has been done by the oculists in the Argentine, Malbràn, Adrogue, Lagos and Sverdlick.

Malbràn and Adrogue in a paper written in 1938 and again in their book on "Squint" published in 1938, describe four cases of monocular diplopia. Three were demonstrated by means of 
the synoptophore and the fourth by means of the synoptophore and by Tschermak's apparatus for testing retinal congruity. Lagos and Adrogue in 1938, examining a case of very persistent postoperative diplopia in a case of squint, by utilizing the method that Tschermak used in his auto-observations, described another case of monocular diplopia. In October 1938, Sverdlick in a very detailed paper dealing with sensorial retinal correspondence and its examination by means of " after-images" deals in much detail with the subject of monocular diplopia. Malbràn and Adrogue differ completely in their explanations of monocular diplopia from the older authors as, unlike Bielschowsky, Gaudenzi etc., who considered that monocular diplopia was due to the fact that one retinal point was mentally projected to two different positions in space simultaneously, they considered that the image of the eccentric point, which was at times in correspondence with the macula of the other eye, was brought to consciousness simultaneously with the macular image.

It is some years since I met my first case of monocular diplopia. It was discovered by chance and not by design. I had previously observed that in cases where it was very difficult to stimulate macular correspondence by flicker, etc., it was possible to bring to consciousness the congenital space value of the eccentric point which was used for correspondence with the macula of the other eye.

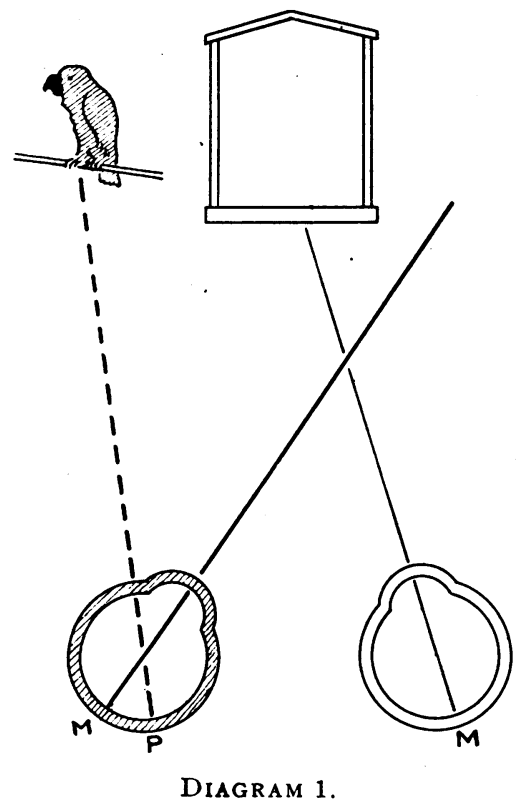

Congenital space value of $P$ is brought to consciousness. 
If we look at the above diagram, the bird is in front of the left squinting eye and the cage is in front of the right fixing eye and if the angle of the squinting eye is say $25^{\circ}$ and the angle of the tubes of the synoptophore is at $20^{\circ}$ so that the image of the bird falls not upon the macula of the left eye, but upon the eccentric point $P$., the congenital space value of the eccentric point $P$. is as in Diagram 1, but if the case has a false correspondence $5^{\circ}$ from the macula the acquired space value of this eccentric point $P$. corresponds to the space value of the macula of the other eye

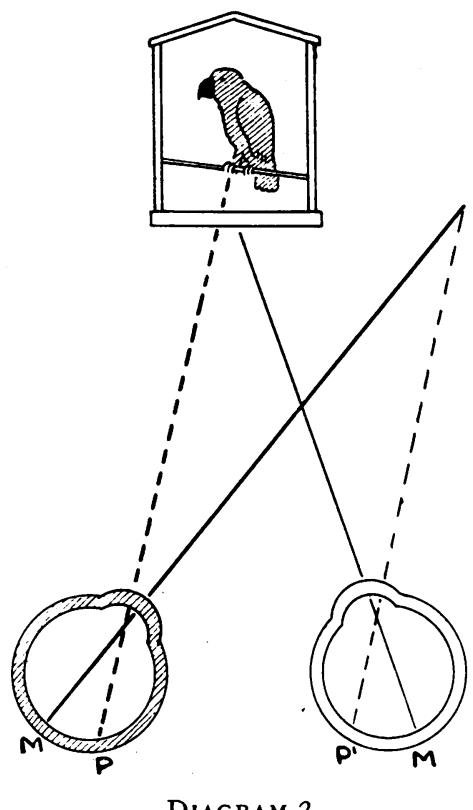

DIAGRAM 2 .

Acquired correspondence is being used and the image of point $P$ is projected to the same point in space as $M$.

and the bird is then seen in the cage as in Diagram 2. It must of course follow that if point $P$. has an acquired space value that all the other retinal points including the macula have also an acquired space value and that an acquired correspondence is being used. Thus, the macular image of this left eye will correspond with the point P.1 in the right eye and will be projected to a point in space in the temporal field of the right eye as in Diagram 3. I have found in such cases (Diagram 2) that by stimulating point $P$. by repeated fluctuation of the light in front of the squinting eye the bird will move and appear on the left of the cage. At first it may be quite close to the cage, but if the tubes are converged a little more, then the bird may again move into the 


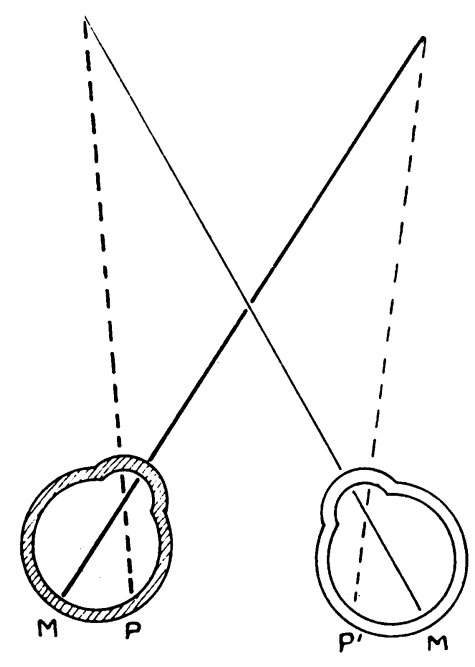

Diagram 3.

Macular images are projected to different points in space when acquired correspondence is used.

cage, but at an angle which is still a little less than the true angle of the squint, i.e., the patient is now using another eccentric point to correspond with the macula of the other eye but this point is nearer to the macula of the squinting eye than the previous point. Finally by repeating this process, macular correspondence can be obtained, and when this happens, it then follows that every retinal point is now using its congenital space value. My first case of monocular diplopia occurred in a child with very poor vision in the squinting eye. I tried to stimulate the macula by means of flicker to teach him to fix and he suddenly told me that he could see two images with this eye. Unfortunately, I could not study this case in detail. He was very young and not very intelligent. It was with my fourth case that I was able to study this condition. This was a case of alternating strabismus dating from the first year of life with no macular correspondence and it resisted all our efforts to elicit normal correspondence by stimulating the macula. He had an abnormal indefinite correspondence some distance from the macula and I tried stimulating the abnormal correspondence as I have previously described. I made him fix with the right eye and stimulated the abnormal corresponding point in the left eye by means of fluctuation of the light and he suddenly saw one parrot inside the cage, with another dim, vague parrot on the left of the cage. On prolonged stimulation, the parrot inside the cage disappeared and only the parrot on the left remained. In the manner previously described, I finally 


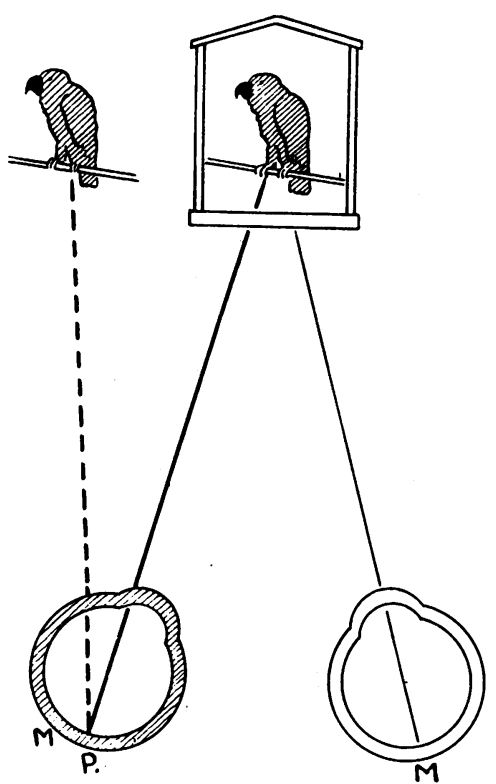

Diagram 4-Case of Convergent Squint.

Monocular diplopia obtained by stimulation of the acquired corresponding point.

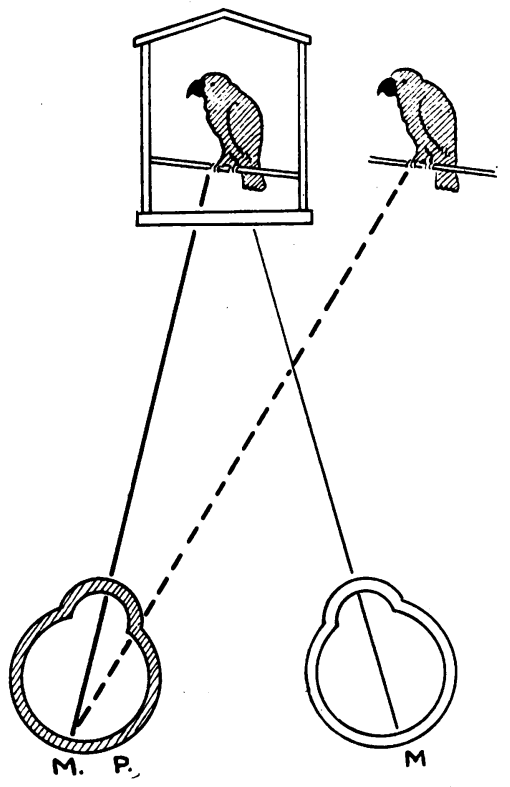

Diagram 5-Case of Convergent Squint.

Monocular diplopia obtained by stimulation of the macula of an eye which has an acquired and congenital correspondence. 
managed to teach him to get a normal correspondence and later I was able to obtain monocular diplopia by stimulation of the macula or the abnormal corresponding point. When a macular correspondence was being used and the macula was stimulated the second bird appeared on the right of the cage, i.e., there was in this case a crossed monocular diplopia with the macula. Bielschowsky says that monocular diplopia with the macula is not obtained, but I have obtained it on various occasions, and I think that it probably helps to explain why when his patient fixed eccentrically with the left eye, the left image was dim, but that when he learned to fix with the macula of the left eye, it was his right image which was dim, this image being due to the acquired space value of the macula. Unfortunately, war has prevented me from studying in detail 33 cases of monocular diplopia which I have managed to elicit and therefore this paper is not so complete as I could wish it to be.

Seventy cases of squint with abnormal correspondence were tested for monocular diplopia. It is usually only possible to test for monocular diplopia in those cases where there is a certain degree of intelligence on the part of the patient. Before the age of six, it is rarely possible, but interest on the part of the patient is the most essential factor. Tests have been made, in some cases many times, either by stimulating the eccentric corresponding point or the macula of the squinting eye by fluctuation of the light of the synoptophore. As far as possible, no suggestion of what might occur was made to the patient. The child was simply asked to state what he saw and, if he saw two images with the one eye, he was asked to state, if possible, the position of the images, which image was clearest and what the colours of the second image were like. If the monocular diplopia was seen with an eccentric point on the nasal part of the retina and he was asked to fix either image, the eye would turn out to take up fixation with the macula. If he was asked to fix either image, and the corresponding eccentric point was on the temporal side of the retina, the eye would turn in to take up fixation with the macula. On stimulating the macula, and obtaining monocular diplopia, either no movement was observed or the eye would make a small movement and then return to its original position when the patient was asked to fix either image. In all cases, the image which was not being fixated would disappear.

33 of the 70 cases obtained monocular diplopia.

51.2 per cent. on stimulation of the false corresponding point.

33.3 per cent. on stimulation of both the false corresponding point and the macula.

15.2 per cent. on stimulation of the macula only. 
It is interesting to note that of these cases tested with monocular diplopia 78 per cent. were not comitant, and without monocular diplopia 81 per cent. were not comitant, that is to say, they all showed some definite lesion, either paresis or over action of a muscle. At operation, 7.7 per cent. were found to have abnormal muscle insertion.

14.4 per cent. of cases with monocular diplopia were associated with nystagmus.

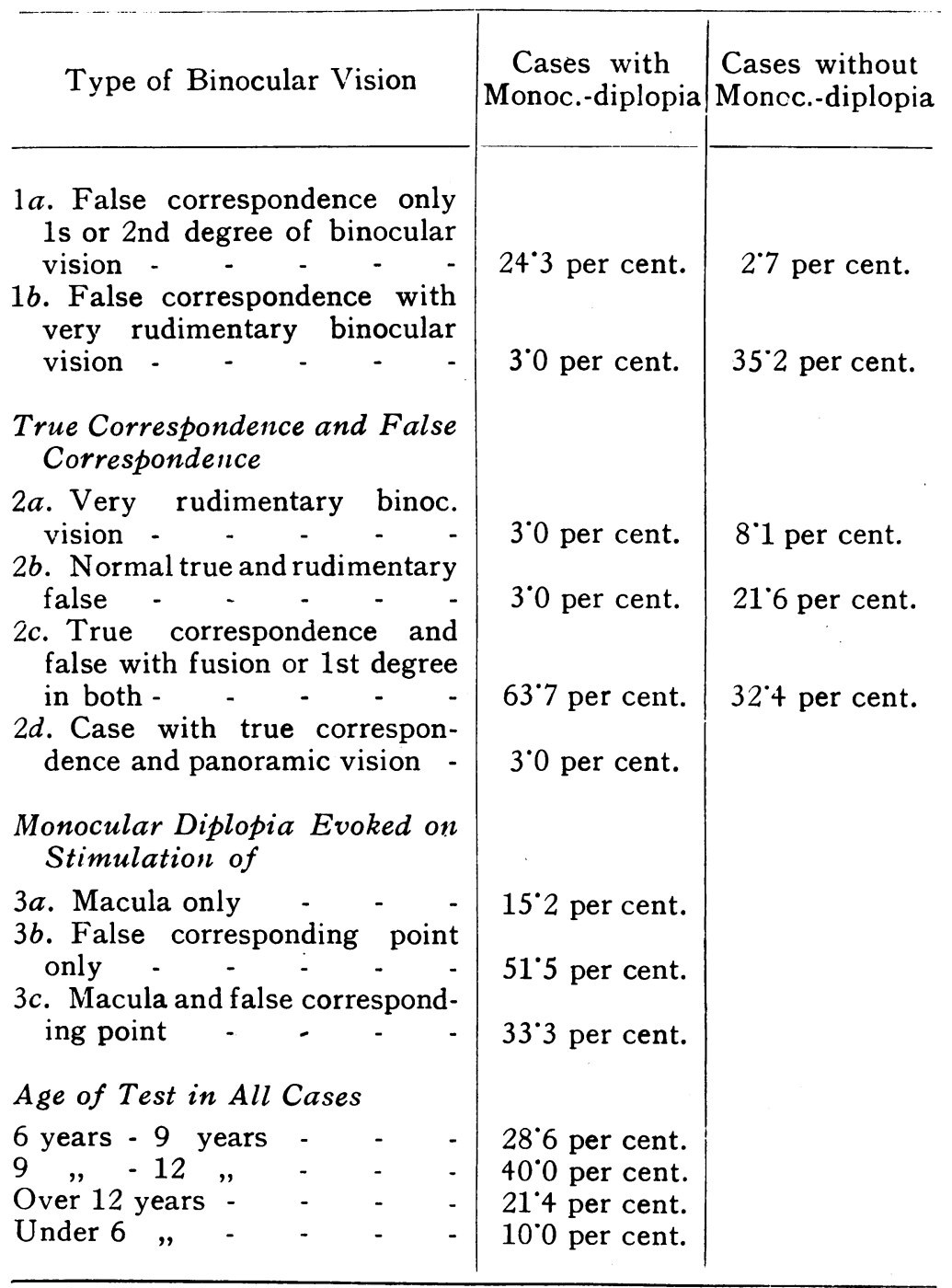




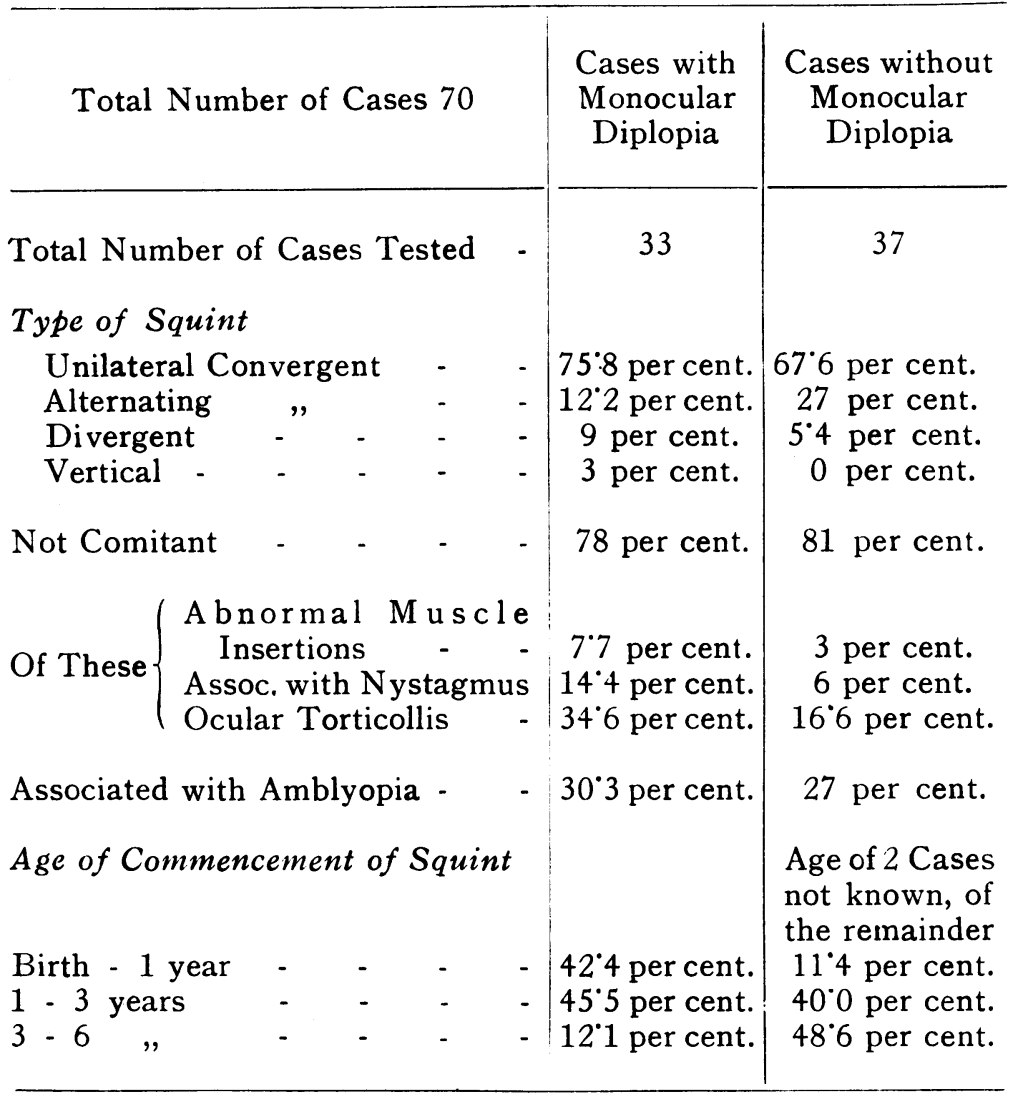

6 per cent. of cases without monocular diplopia were associated with nystagmus.

Ocular torticollis was present in 34.6 per cent. of the cases with monocular diplopia.

Ocular torticollis was present in 16.6 per cent. of the cases without monocular diplopia.

Amblyopia was present in 30.3 per cent. of the cases with monocular diplopia.

Amblyopia was present in 27 per cent. of the cases without monocular diplopia.

Other cases had had an amblyopia which had improved on occlusion. The average age of commencement of the squint was usually younger in those with monocular diplopia as can be seen from the above table.

Cases with a false correspondence only and some degree of binocular vision with this false correspondence usually had a monocular diplopia, but those where the binocular vision was 
very rudimentary had no monocular diplopia. Cases with a true and false correspondence, where the true was strong and the false weak, usually had no monocular diplopia. The majority of cases in which monocular diplopia could be evoked were those which had an equal degree of binocular vision when they used the eccentric corresponding point or the macula. In the majority of cases it was more common to evoke monocular diplopia by stimulation of the eccentric point as in this case it was bringing the congenital space value of this point to consciousness. It was less easy to bring monocular diplopia to consciousness by stimulating the macula and usually occurred in those cases where the acquired correspondence was stronger, but it proved the presence of a congenital correspondence. In cases where stimulation of both the maculae or the eccentric point evoked monocular diplopia, the degree of binocular vision was usually equal, whichever correspondence vas used. $4 \cdot 2$ per cent. of cases complained of monocular diplopia in everyday life.

\section{Explanation of the Phenomenon}

In seeking an explanation of the phenomenon, it is necessary to consider the congenital space value of retinal points as conceived by Hering and the formation of an abnormal retinal correspondence. The macula is the starting point of orientation and each retinal point has a definite orientation in space with regard to the macula. At the same time, each retinal point has a morphological space value corresponding to the space value of a retinal point in the other eye. To a certain extent, we perfect our knowledge of the orientation of objects in space with regard to our own body during the act of binocular vision or in the act of monocular vision, by the rombination of the sensations of touch and sight. The normal correspondence of the two maculae can be changed if, by some means during the early years of life, it becomes impossible for the patient to direct both his visual axes towards the object that he wishes to fix. In a large number of cases of squint in children which can be investigated soon after the commencement of the squint, normal correspondence is to be found and also diplopia can be elicited by means of red and green goggles and the double images are situated at a distance from one another corresponding to the angle of the squint. Donders observed that after a time there was an overlapping in the visual fields in some cases of convergent squint without any change, however, in the correspondence of the retinal points; this statement was later repeated by Javal, and von Graefe observed the extension of the binocular field in cases of divergent strabismus. In this stage, the patient has learnt that his eyes are deviating and he also has 
learnt by the association of sight and touch the orientation of an object in space with regard to his own body : that is to say, if one meets a squint which fulfils these conditions and it is examined on a synoptophore, if the patient is told to fix with the sound eye, he will orientate correctly with respect to his own body an object seen by the peripheral parts of the retina of the deviated eye, but he still has normal correspondence. At the same time, he is not completely certain of the orientation of this image with respect to the image fixed by the sound eye; for example, if a child is fixing the cage with his sound eye, and the tubes of the synoptophore are placed parallel with the parrot in the tube in front of the deviating eye, he will point correctly to the position of the parrot and will not point as though the eccentric point had the congenital space value; i.e., in a case of convergent squint, he will point in front and not to the temporal side. If, however, he is asked to tell you the relationship of the two images to each other, he will not be able to indicate this exactly, although he is capable of seeing both simultaneously. If he is tested with red and green goggles, the two images are usually seen fairly close together, but he is uncertain of the exact distance between them, and the distance may vary. There is now a conflict between his sense of touch which is teaching him that one and not two images are present and his congenital system of the orientation of images perceived by dissimilar points. If he forms a false correspondence and ignores the congenital correspondence, the images of the dissimilar points will appear to be at the same place in space but if he uses both the true and the false correspondences, then he will orientate at times correctly with respect to his body and at others incorrectly according to whether he uses the acquired or the congenital correspondence. In this condition, where both a false and a true correspondence are present, each retinal point must possess two space values, i.e., a congenital and an acquired, and one retinal point can orientate itself in two entirely different positions in space with no movement of the eyes having taken place. Most cases that squint from birth or within the first few months of life, who have any appreciable angle of squint, usually only possess an acquired correspondence by the time they are old enough to have their binocular vision tested and these cases are the worst to treat, as from the very earliest years they have used their eyes in an abnormal manner; and the associational fibres which are used during the early years of life are the most fixed; but even in some of these cases it is possible to evoke a monocular diplopia by stimulating the eccentric corresponding point. If we stimulate the eccentric point corresponding to the macula of the other eye, we can make the patient conscious of the congenital and acquired space value of this point simultaneously and this causes monocular 
diplopia. We can now see how stimulation of a point on the nasal part of the retina, which is using an acquired space value, results in an uncrossed diplopia because it brings to consciousness the congenital space value of this point and the second image is naturally on the temporal side of the first. Naturally, stimulation of the macula when the congenital space value is being used, results in the second image being seen on the nasal side of the first image, i.e., there is a crossed diplopia due to the evoking of the acquired space value. There are certain exceptions to this condition, as, for example, where a squint has had a false correspondence which has now moved nearer to the macula. In this case, stimulation of the newly acquired corresponding point will result in a crossed and not an uncrossed diplopia. The converse of the position of images, both on stimulation of the macula or of the eccentric point, holds for the case of a divergent squint.

\section{Some Observations Associated with the Second Image in Monocular Diplopia}

1. Generally in the beginning it is much dimmer than the first image.

2. Its colours are less well defined.

3. In the beginning, it is very vague and disappears easily.

4. It is difficult for the patient to orientate its position in space.

5. On prolonged stimulation, one or other image will disappear but if the congenital space value is the stronger, this image will remain.

6. On asking the patient to fix either image caused by the stimulation of the eccentric point corresponding to the macula of the other eye, the eye will turn to take up fixation with the macula and the non-fixated image will disappear,

7. On telling the child to fix either image excited by stimulation of the macula, there will be no movement of the eye or there will be a slight flicker and the eye later returns to its original position and the non-fixated image will disappear.

\section{Conclusions}

This condition of monocular diplopia is caused by bringing to consciousness simultaneously the congenital and the acquired space value of a retina. At the same time, it gives one a link between the contrary theories of the nativists, the empiricists and the projection theory of Nagel. The fact that monocular diplopia 
can be stimulated in cases which have suffered from squint since birth and have only been able to use an acquired space value, proves the existence of some degree of congenital space value of retinal points. In cases where it is very difficult to obtain macular correspondence, stimulation of the abnormal corresponding point may cause the phenomenon of monocular diplopia to take place, thus evoking a true space value of the retinal point. Prolonged stimulation will cause the image due to the acquired space value to disappear and this process may be the first step towards establishing normal retinal correspondence.

\section{REFERENCES}

\section{MONOCULAR DIPLOPIA}

Remy.-'False Projection. Monocular Triplopia.' Recueil d'Ophtal., p. 350, 1904.

GaUdenZI. - Les erreurs de la projection dans le Strabisme et leurs rapports avec sa therapie. Rev. gen.d'Ophtal., Vol. XVI, p. 529-543, 1897.

Travers.-Concomitant Strabismus.

DONDERS. - Accommodation and Refraction of the Eyes, 1864.

TSCHERMAK.- ' Ueber abnormale Sehrichtengemeinschaft der Netzhaut.' Arch. f. Ophthal, 1899.

Bielschowsky, A.- ' Ueber monokuläre Diplopie ohne physikalische Grundlage.' Bet. u.' d. Versamm.d'Ophthal. Gellsch. Heidelb., Vol. XXVI, p. 93-104, 1897-98.

Bielschowsky, A.-' Ueber monokuläre Diplopie ohne physikalische Grundlage nebst Bemerkungen ueber das Sehen Schielenden.' Arch. f. Ophthal., p. $143,1898$.

Classen.-Arch.f. Ophthal, B. XVI, s. 126.

JAVAL. -Ann. d'ocul, T. LIV.p. 25, 1865.

JaVAL. -Manuel de Strabisme.

Adrogue y Lagos.- 'A proposito de un caso de diplopia permanente postoperatoria.' Archivos de Ophthal. de Buenos Aires, p. 514, October 1938.

Helmholtz.-Physiological Optics.

Malbran y AdRogue. - Sobre la Diplopia Monocular. :Archivos Oftal. de Buenos Aires, p. 141, March, 1938.

José Sverolick.-Presentacion de una Lampara para Post Imagenes y de un Aparato Congenente Tipo Tschermak. Archivos de Oftal. de Buenos Aires, p. 571, October 1938.

MALBRAN y ADROGUe.-Estrabismo, p. 170.

Joseph Gerstmann und Alfred Kestenbaum.-' Monokuläres Doppelsehen bei cerebralen Erkrankungen, p. 193.

Dr. Alfred Graefe.-Das Sehen der Schielenden.

VON GRAEFE.-Arch.f. Ophthal., B.VI., s. 284-289, 1855.

VON GRAEFE. - ' Nach Fragliche Bemerkungen ueber Incongruenz der Netzhaut.' Arch. f. Ophthal, Band I, s. 294-299, 1854. 